\title{
Bithienopyrroledione vs. thienopyrroledione based copolymers: dramatic increase of power conversion efficiency in bulk heterojunction solar cells $\dagger$
}

Cite this: Chem. Commun., 2017 53,3543

Received 19th January 2017, Accepted 6th March 2017

DOI: 10.1039/c7cc00501f

rsc.li/chemcomm

\author{
Xiaolan Qiao, $\ddagger^{\mathrm{a}}$ Weichao Chen, $\ddagger^{\mathrm{b}}$ Qinghe Wu, ${ }^{\mathrm{a}}$ Shiqian Zhang, ${ }^{\mathrm{C}}$ Hongzhuo Wu, ${ }^{\mathrm{a}}$ \\ Zhiqiang Liu, ${ }^{c}$ Renqiang Yang ${ }^{{ }^{b}}$ and Hongxiang Li*a
}

\begin{abstract}
Bithienopyrroledione (bi-TPD) based polymers $\mathrm{P} 1$ and $\mathrm{P} 2$ are designed and synthesized. Photovoltaic devices based on $\mathrm{P1}: \mathrm{PC}_{71} \mathrm{BM}$ and $\mathrm{P2}: \mathrm{PC}_{71} \mathrm{BM}$ blend films show power conversion efficiencies (PCEs) of $\mathbf{8 . 2 2 \%}$ and $\mathbf{9 . 0 8 \%}$, respectively, whereas devices based on their thienopyrroledione (TPD)-based analogue $\mathrm{P} 3$ and $\mathrm{PC}_{71} \mathrm{BM}$ blend films display a PCE of $5.10 \%$.
\end{abstract}

Polymer solar cells (PSCs) have been intensively investigated in recent years due to their features of low cost, flexibility, and light weight. $^{1-5}$ The development in active layer materials, interfacial materials, and device processing technologies has improved the power conversion efficiencies (PCEs) of PSCs greater than $10 \% .^{6-12}$ In view of the active layer materials, donor-acceptor (D-A) type polymers have attracted great attention due to their advantages in tuning the absorption spectra, HOMO/ LUMO energy levels, intermolecular interactions and molecular orientations, and hence numerous D-A type semiconductor polymers have been synthesized and used as donors in bulk heterojunction (BHJ) structure solar cells. ${ }^{13,14}$ To date, D-A polymers with PCEs over $8 \%$ have rarely been reported and most of them employ benzo[1,2,5]thiadiazole and fluorinated thieno[3,4- $b]$ thiophene derivatives as electron deficient units. ${ }^{15-24}$ Thus, the exploration of new electron-deficient units (acceptor units) is urgently required for the development of high performance

\footnotetext{
${ }^{a}$ Key Laboratory of Synthetic and Self-assembly Chemistry for Organic Functional Molecules, Shanghai Institute of Organic Chemistry, Chinese Academy of Sciences, Shanghai, 200032, China. E-mail: lhx@mail.sioc.ac.cn

${ }^{b}$ CAS Key Laboratory of Bio-based Materials, Qingdao Institute of Bioenergy and Bioprocess Technology, Chinese Academy of Sciences, Qingdao, 266101, China. E-mail: yangrq@qibebt.ac.cn

${ }^{c}$ State Key Laboratory of Crystal Materials, Shandong University, Jinan 250100, China

$\dagger$ Electronic supplementary information (ESI) available: Synthesis of the polymers, device fabrication and characterization, cyclic voltammetry, $J-V$ curves and photovoltaic parameters of PSCs based on polymer: $\mathrm{PC}_{71} \mathrm{BM}, \mathrm{AFM}$ images of the blend films and $J-V$ curves of vertical diodes for hole (electron) only devices. See DOI: $10.1039 / \mathrm{c} 7 \mathrm{cc} 00501 \mathrm{f}$

\$ These authors contributed equally.
}

D-A polymers and the study of the relationships between polymer chemical structures and properties.

Thieno[3,4]pyrrole-4,6-dione (TPD) based polymers are widely used as electron donors in bulk heterojunction solar cells and a record PCE of $8.5 \%$ has been reported for TPD-benzodithiophene copolymerized polymers by using a classical device configuration. ${ }^{25-28}$ As a derivative of TPD, bithienopyrroledione $\left(1,1^{\prime}\right.$-bithieno[3,4-c]pyrrole-4,4',6,6'-tetraone, bi-TPD) has a good planar structure and stronger electron-withdrawing ability than TPD, ${ }^{29-31}$ making it a good candidate as an acceptor unit for D-A polymers. However, bi-TPD based D-A polymers have rarely been investigated in PSCs. This might be partially because of the commonly accepted view that the large internal dipole moment along the polymer chain facilitates charge separation in PSCs and thus results in high PCE, which were examined by Yu's and Tsige's groups on polymers PTB7 and PBB3. ${ }^{32,33}$ In this study, we designed and synthesized two bi-TPD based polymers P1 and P2 (Scheme 1) and investigated their application as donor materials in PSCs. The P1 and P2 based cells exhibit PCEs of $8.22 \%$ and $9.08 \%$ with a traditional device configuration of ITO/PEDOT:PSS/P1 (P2):PC ${ }_{71} \mathrm{BM} /$ $\mathrm{Ca} / \mathrm{Al}$, much higher than that of the cell of TPD based analogue $\mathbf{P 3}$ (PCE: $5.10 \%$ ) and the highest PCE value reported for bi-TPD

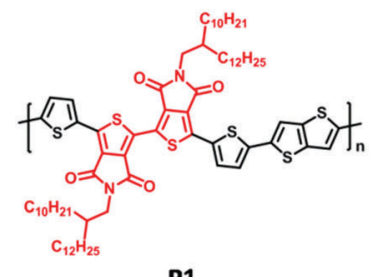

P1

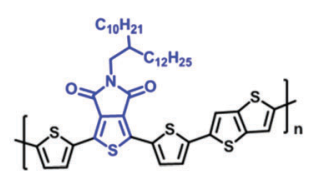

P4

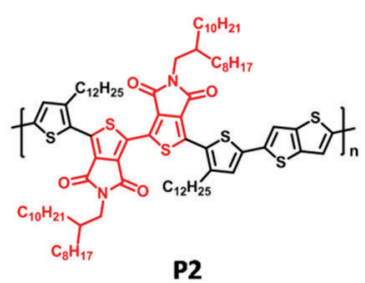

P2

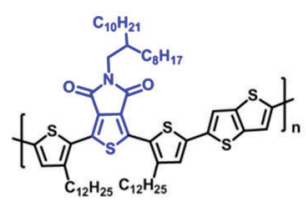

P3
Scheme 1 Chemical structures of polymers P1-P4 
(a)
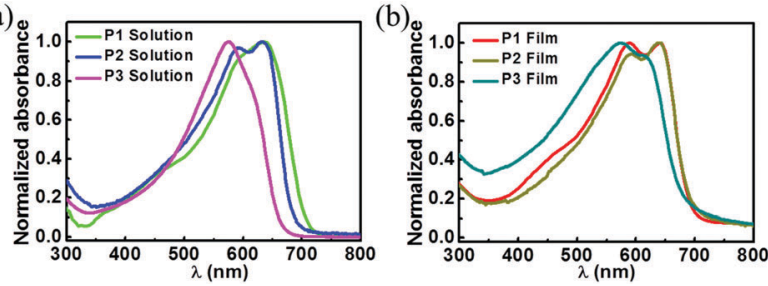

Fig. 1 UV-vis absorption spectra of P1-P3 in dilute O-DCB solutions (a) and thin films (b).

contained polymers. These results demonstrate that bi-TPD based polymers have great potential for application in PSCs.

P1 and P2 were synthesized through conventional Stille coupling of a stannyl reagent of thieno[3,2-b]thiophene with the corresponding 5,5'-bis[5-bromo-3-akylthiophen]-1,1'-bithieno[3,4-c]pyrrole-4, $4^{\prime}, 6,6^{\prime}$-tetraone. For comparison, $\mathbf{P}^{34}$ and $\mathbf{P 4}$, the monoTPD based analogues of $\mathbf{P 1}$ and $\mathbf{P 2}$, were also synthesized using the Stille coupling reaction (Scheme S1 in the ESI $\dagger$ ). Their number-average molecular weights $\left(M_{\mathrm{n}}\right)$ were measured using high temperature $\left(150^{\circ} \mathrm{C}\right)$ gel-permeation chromatography (GPC) in 1,2,4-trichlorobenzene using polystyrene as the standard. The $M_{\mathrm{n}} / \mathrm{PDI}$ (polydispersity index) values were $82.9 \mathrm{kDa} / 2.88$ for P1, $53.3 \mathrm{kDa} / 2.29$ for $\mathbf{P 2}, 154 \mathrm{kDa} / 4.99$ for $\mathbf{P} 3$ and $7.1 \mathrm{kDa} / 2.83$ for $\mathbf{P 4}$. The low molecular weight of $\mathbf{P 4}$ was due to its poor solubility, and solar cell devices based on $\mathbf{P 4}$ were not fabricated and investigated because of its lower $M_{\mathrm{n}}$.

The UV-vis absorption spectra of copolymers P1-P3 were measured by a UV-vis spectrophotometer in $o$-dichlorobenzene (o-DCB) solution and in thin films spin-coated from $o$-DCB solution (Fig. 1). All polymers showed $0-0 / 0-1$ peaks in solution and in thin films. For P1, the $0-1$ peaks in solution and films were located at $588 \mathrm{~nm}$, and the $0-0$ peak was at $634 \mathrm{~nm}$ in solution and at $640 \mathrm{~nm}$ in films. For P2, similar to P1, the $0-1$ peaks were at $592 \mathrm{~nm}$ in solution and films, and the $0-0$ peak was shifted from $632 \mathrm{~nm}$ in solution to $640 \mathrm{~nm}$ in films. The $0-1$ and $0-0$ absorptions of $\mathbf{P 3}$ were at 575 and $614 \mathrm{~nm}$ in both solution and thin films. The optical band gaps estimated from thin film absorptions were 1.80, 1.80, and $1.84 \mathrm{eV}$ for P1, P2, and P3, respectively. The electrochemical properties of the $\mathbf{P 1}$ and $\mathbf{P} \mathbf{2}$ thin films were investigated through cyclic voltammetry (CV) (Fig. S1, ESI $\dagger$ ). P1 and P2 displayed a quasi-reversible oxidation process with redox potentials located at 1.24 and $1.22 \mathrm{~V} v s$. SCE, respectively, and the HOMO energy level was $-5.61 \mathrm{eV}$ for $\mathbf{P 1}$ and $-5.59 \mathrm{eV}$ for $\mathbf{P 2}$. The LUMO energy levels calculated from the HOMO levels and optical band gaps were $-3.81 \mathrm{eV}$ for $\mathbf{P 1}$ and $3.79 \mathrm{eV}$ for P2. The HOMO/LUMO energy levels of $\mathbf{P 1}$ and $\mathbf{P 2}$ were much lower than that of $\mathbf{P 3}$ (HOMO/LUMO: $-5.07 /-3.23 \mathrm{eV}) .^{34}$ The energy levels of the P1-P3 and PC ${ }_{71}$ BM (LUMO: $-4.30 \mathrm{eV}$; HOMO: $-6.00 \mathrm{eV}$ ) exhibited a suitable cascade stage for exciton dissociation, suggesting their potential application in polymer: $\mathrm{PC}_{71} \mathrm{BM}$ blend solar cells.

The photovoltaic properties of polymers P1-P3 were investigated using the conventional device structure of ITO/PEDOT:PSS/polymer: $\mathrm{PC}_{71} \mathrm{BM} / \mathrm{Ca} / \mathrm{Al}$. The current density-voltage $(J-V)$ characteristics of the optimized devices are illustrated in Fig. $2 \mathrm{a}$. The performance (a)
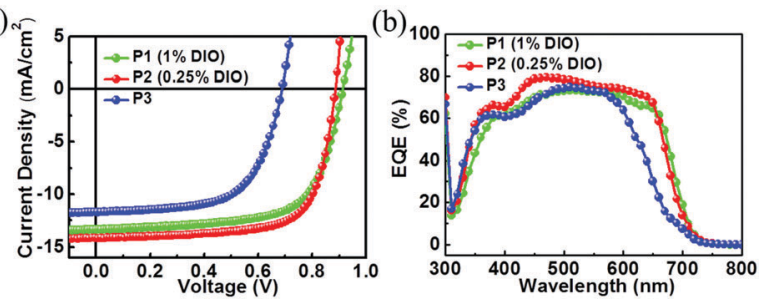

Fig. $2 \mathrm{~J}-V$ curves (a) and the corresponding EQE curves (b) of the polymer:PC $\mathrm{C}_{71} \mathrm{BM}$ solar cells with optimal performance.

Table 1 Photovoltaic parameters of PSCs based on polymer:PC ${ }_{71} B M$

\begin{tabular}{|c|c|c|c|c|}
\hline Polymers $^{a}$ & $V_{\mathrm{oc}}(\mathrm{V})$ & $J_{\mathrm{sc}}\left(\mathrm{mA} \mathrm{cm}^{-2}\right)$ & FF (\%) & $\operatorname{PCE}^{b}(\%)$ \\
\hline P1 & 0.91 & 13.45 & 67.18 & $8.22(8.02 \pm 0.20)$ \\
\hline P2 & 0.89 & 14.15 & 72.13 & $9.08(8.92 \pm 0.16)$ \\
\hline P3 & 0.69 & 11.70 & 63.15 & $5.10(4.89 \pm 0.21)$ \\
\hline
\end{tabular}

${ }^{a}$ Blend ratios of P1:PC $\mathrm{PC}_{71} \mathrm{BM}(\mathrm{w} / \mathrm{w})$ were $1: 2$ with $1 \%$ DIO, P2:PC ${ }_{71} \mathrm{BM}$ $(\mathrm{w} / \mathrm{w})$ were $1: 2$ with $0.25 \%$ DIO and P3:PC ${ }_{71} \mathrm{BM}(\mathrm{w} / \mathrm{w})$ was fixed at $1: 1.5$ without DIO. ${ }^{b}$ In parentheses are average values based on more than 10 devices.

of the device was first optimized by using different polymer: $\mathrm{PC}_{71} \mathrm{BM}$ weight ratios (Table S1, ESI $\dagger$ ). The optimal weight ratio for bi-TPD based polymers $\mathbf{P 1}$ and $\mathbf{P 2}$ to $\mathrm{PC}_{71} \mathrm{BM}$ was found to be $1: 2$, and that for $\mathbf{P} 3$ to $\mathrm{PC}_{71} \mathrm{BM}$ was $1: 1.5$. Then, the effect of the 1,8-diiodooctane (DIO) additive on the device performance was investigated (Fig. S2-S4 and Table S2, ESI $\dagger$ ). The experimental results show that (Table 1) the cells of P1: $\mathrm{PC}_{71} \mathrm{BM}$ with $1 \%$ DIO exhibited an optimal PCE of $8.22 \%$ with a $V_{\text {oc }}$ of $0.91 \mathrm{~V}$, a $J_{\mathrm{sc}}$ of $13.45 \mathrm{~mA} \mathrm{~cm}{ }^{-2}$, and a $\mathrm{FF}$ of $67.18 \%$. For $\mathbf{P 2}: \mathrm{PC}_{71} \mathrm{BM}$ based devices, a PCE up to $9.08 \%$ with a $V_{\text {oc }}$ of $0.89 \mathrm{~V}$, a $J_{\mathrm{sc}}$ of $14.15 \mathrm{~mA} \mathrm{~cm}{ }^{-2}$, and a $\mathrm{FF}$ of $72.13 \%$ was observed upon addition of $0.25 \%$ DIO. For P3: $\mathrm{PC}_{71} \mathrm{BM}$ based devices, the optimal PCE was $5.10 \%$ with a $V_{\mathrm{oc}}$ of $0.69 \mathrm{~V}$, a $J_{\mathrm{sc}}$ of $11.70 \mathrm{~mA} \mathrm{~cm}^{-2}$, and a FF of $63.15 \%$. This PCE value is comparable to the reported TPD and 2,5-di(thiophen-2-yl)thieno[3,2-b] thiophene (DT-TT) based polymers. ${ }^{35}$ Apparently, the $V_{\text {oc }}$ of $\mathbf{P 1}$ and $\mathbf{P 2}$ based solar cells was significantly larger than that of $\mathbf{P} \mathbf{3}$ based devices. This is consistent well with the deeper HOMO energy levels of the bi-TPD based polymers. The PCEs of $\mathbf{P 1}$ and $\mathbf{P 2}$ based devices may be further improved through device engineering similarly to that of PTB7-Th:PC ${ }_{71} \mathrm{BM}$ based solar cells.

The photo-response of the solar cells based on these polymers was investigated using their external quantum efficiencies (EQEs), and the EQE curves of the optimal devices are illustrated in Fig. 2b. The P1: $\mathrm{PC}_{71} \mathrm{BM}$ and $\mathbf{P 2}: \mathrm{PC}_{71} \mathrm{BM}$ devices showed a broader photo-response than the $\mathbf{P}$ : $\mathrm{PC}_{71} \mathrm{BM}$ device, consistent with their thin film absorptions. The P2: $\mathrm{PC}_{71} \mathrm{BM}$ device exhibited the highest average EQE values among the three devices. The current density calculated from the EQE curves with a standard solar spectrum (AM 1.5G) was 13.25, 13.92, and $11.36 \mathrm{~mA} \mathrm{~cm}^{-2}$ for P1-P3, respectively, agreeing well with the ones obtained from $J-V$ measurements.

To elucidate the observed performance of P1-P3 based solar cells, we explored the morphological features of the optimal blend films using transmission electron microscopy (TEM) and 


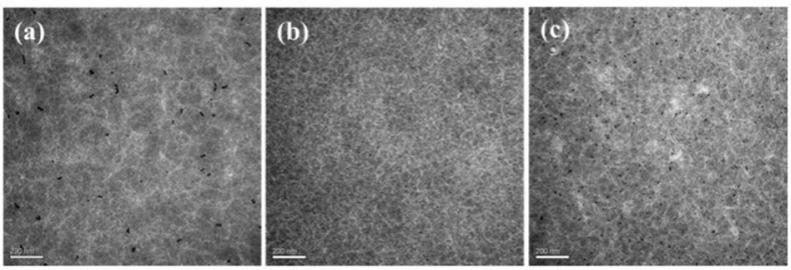

Fig. 3 TEM images of the polymer:PC $\mathrm{C}_{71} \mathrm{BM}$ films: (a) $\mathrm{P} 1: \mathrm{PC}_{71} \mathrm{BM}$; (b) P2:PC $\mathrm{C}_{71} \mathrm{BM}$; and (c) P3:PC ${ }_{71} B M$. The scale bars in the images are $200 \mathrm{~nm}$.

atomic force microscopy (AFM). Fig. 3 illustrates the TEM images of the blend films. All the films exhibited obvious dark and light domains, corresponding to the aggregates of $\mathrm{PC}_{71} \mathrm{BM}$ and the polymer, respectively. For P1 (P2): $\mathrm{PC}_{71} \mathrm{BM}$ films, nanofibrillar-like aggregates were formed and distributed throughout the blend films, resulting in an interpenetrating network. This kind of morphological feature is more favorable for efficient exciton separation and diffusion. $\mathbf{P} 3: \mathrm{PC}_{71} \mathrm{BM}$ films showed similar morphological features to the other two blend films. However, some aggregated structures of $\mathbf{P 3}$ (high brightness areas) were observed. AFM images revealed that $\mathbf{P 1}: \mathrm{PC}_{71} \mathrm{BM}$ films were comprised of large size grains with an RMS value of $4.21 \mathrm{~nm}$ (Fig. S5, ESI $\dagger$ ). Compared to P1:PC ${ }_{71} \mathrm{BM}$ films, $\mathbf{P 2}: \mathrm{PC}_{71} \mathrm{BM}$ films exhibited smaller size domains and smoother surfaces with an RMS value of $1.73 \mathrm{~nm}$. The RMS values of $\mathbf{P 3}: \mathrm{PC}_{71} \mathrm{BM}$ films were larger than $9 \mathrm{~nm}$ due to the formation of aggregated structures, which is consistent with the TEM results.

The crystallinity and molecular packing of the polymers in the active layers were probed using $2 \mathrm{D}$ grazing incidence $\mathrm{X}$-ray diffraction (2D-GIXD) (Fig. 4). P1-P3 were crystalline and adopted edge-on and face-on co-orientations in the blend films, as proved by the (100) diffraction peaks in both the $q_{x y}$-axis and the $q_{z}$-axis. Moreover, $\pi-\pi$ stacking diffractions ( 010 peaks) were observed in the $q_{z}$-axis and the $\pi-\pi$ stacking distances were calculated to be $3.52,3.61$, and $3.60 \AA$ for P1, P2 and P3, respectively. The crystalline nature and co-existence of the edge-on and face-on packing structures of the films facilitated charge carrier transport in polymer solar cell, leading to high photovoltaic performance.

The hole and electron transport properties of the optimal polymer: $\mathrm{PC}_{71} \mathrm{BM}$ films in the direction perpendicular to the substrate were evaluated using space-charge-limited-current (SCLC) measurements. The $J-V$ curves are shown in Fig. S6 (ESI $\dagger$ ). For P1: $\mathrm{PC}_{71} \mathrm{BM}$ films, the calculated electron $\left(\mu_{\mathrm{e}}\right)$ and hole $\left(\mu_{\mathrm{h}}\right)$ mobilities were $4.48 \times 10^{-4} \mathrm{~cm}^{2} \mathrm{~V}^{-1} \mathrm{~s}^{-1}$ and $1.99 \times 10^{-4} \mathrm{~cm}^{2} \mathrm{~V}^{-1} \mathrm{~s}^{-1}$ with a
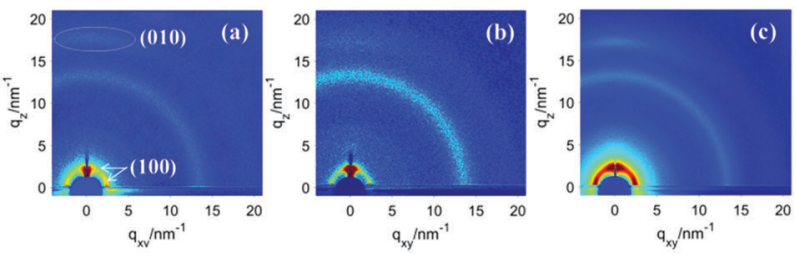

Fig. 4 2D-GIXD images of the polymer:PC $C_{71} B M$ films: (a) $P 1: P C_{71} B M$; (b) P2:PC ${ }_{71} \mathrm{BM}$; and (c) P3:PC ${ }_{71} \mathrm{BM}$. $\mu_{\mathrm{e}} / \mu_{\mathrm{h}}$ ratio of 2.25. For $\mathbf{P} 2: \mathrm{PC}_{71} \mathrm{BM}$ films, the calculated $\mu_{\mathrm{e}}$ and $\mu_{\mathrm{h}}$ were $3.86 \times 10^{-4} \mathrm{~cm}^{2} \mathrm{~V}^{-1} \mathrm{~s}^{-1}$ and $2.49 \times 10^{-4} \mathrm{~cm}^{2} \mathrm{~V}^{-1} \mathrm{~s}^{-1}$ with a $\mu_{\mathrm{e}} / \mu_{\mathrm{h}}$ ratio of 1.55. For P3:PC ${ }_{71} \mathrm{BM}$ films, the calculated $\mu_{\mathrm{e}}$ and $\mu_{\mathrm{h}}$ were $3.57 \times 10^{-4} \mathrm{~cm}^{2} \mathrm{~V}^{-1} \mathrm{~s}^{-1}$ and $1.35 \times 10^{-4} \mathrm{~cm}^{2} \mathrm{~V}^{-1} \mathrm{~s}^{-1}$ with a $\mu_{\mathrm{h}} / \mu_{\mathrm{e}}$ ratio of 2.64 . The relatively balanced carrier mobility of P2: $\mathrm{PC}_{71} \mathrm{BM}$ might be an important factor for its higher $\mathrm{FF}$ in solar cells. ${ }^{36}$

In conclusion, new bi-TPD based polymers $\mathbf{P 1}$ and $\mathbf{P} 2$ were designed and synthesized. Their physicochemical properties were investigated. Compared to their TPD-based analogue P3, $\mathbf{P 1}$ and $\mathbf{P 2}$ have deeper HOMO energy levels and exhibit redshifted thin film UV-vis absorption spectra. The photovoltaic characteristics showed that cells based on bi-TPD based polymers P1 and P2 exhibited much higher PCE than that of mono-TPD based polymer P3. The optimal PCE is $8.22 \%$ for P1 cells, 9.08\% for $\mathbf{P 2}$ cells and $5.10 \%$ for $\mathbf{P 3}$ cells. The PCE and FF values of P2 cells are among the highest values reported for single junction solar cells. The blend films of $\mathbf{P 1}$ (P2): $\mathrm{PC}_{71} \mathrm{BM}$ exhibited high crystallinity with face-on and edge-on co-orientations and good phase separation. These results demonstrate that bi-TPD is an excellent electron-deficient unit that is rarely investigated for high PCE polymer semiconductors. Through further material optimization in the side chains and donor units as well as device engineering, we believe, bi-TPD based polymers with higher efficiencies can be envisioned.

This work was supported by the National Natural Science Foundation of China (21474128, 21672252, 61405209, 21672130) and the "Strategic Priority Research Program" of the Chinese Academy of Sciences (XDB12010100). H. Li thanks the Shanghai Synchrotron Radiation Facility (Beamline BL14B1) for providing the beam time.

\section{Notes and references}

1 L. Dou, Y. Liu, Z. Hong, G. Li and Y. Yang, Chem. Rev., 2015, 115, 12633.

2 L. Lu, T. Zheng, Q. Wu, A. M. Schneider, D. Zhao and L. Yu, Chem. Rev., 2015, 115, 12666.

3 F. C. Krebs, N. Espinosa, M. Hösel, R. R. Søndergaard and M. Jørgensen, Adv. Mater., 2014, 26, 29.

4 P. Cheng and X. Zhan, Chem. Soc. Rev., 2016, 45, 2544.

5 Y. J. Cheng, S. H. Yang and C. S. Hsu, Chem. Rev., 2009, 109, 5868.

6 Y. Liu, J. Zhao, Z. Li, C. Mu, W. Ma, H. Hu, K. Jiang, H. Lin, H. Ade and H. Yan, Nat. Commun., 2014, 5, 5293.

7 W. Zhao, D. Qian, S. Zhang, S. Li, O. Inganas, F. Gao and J. Hui, Adv. Mater., 2016, 28, 4734.

8 H. Bin, L. Gao, Z. G. Zhang, Y. Yang, Y. Zhang, C. Zhang, S. Chen, L. Xue, C. Yang, M. Xiao and Y. Li, Nat. Commun., 2016, 7, 13651.

9 J. Chen, C. Cui, Y. Q. Li, L. Zhou, Q. D. Ou, C. Li, Y. Li and J. Tang, Adv. Mater., 2015, 27, 1035.

10 X. H. Ouyang, R. X. Peng, L. Ai, X. Y. Zhang and Z. Y. Ge, Nat. Photonics, 2015, 9, 520.

11 J. Zhang, Y. Zhang, J. Fang, K. Lu, Z. Wang, W. Ma and Z. Wei, J. Am. Chem. Soc., 2015, 137, 8176.

12 Y. Liu, Z. A. Page, T. P. Russell and T. Emrick, Angew. Chem., Int. Ed., 2015, 54, 11485.

13 Y. Li, Acc. Chem. Res., 2012, 45, 723.

14 J. W. Chen and Y. Cao, Acc. Chem. Res., 2009, 42, 1709.

15 M. Wang, D. Cai, Z. Yin, S. C. Chen, C. F. Du and Q. Zheng, Adv. Mater., 2016, 28, 3359.

16 K. Kawashima, T. Fukuhara, Y. Suda, Y. Suzuki, T. Koganezawa, H. Yoshida, H. Ohkita, I. Osaka and K. Takimiya, J. Am. Chem. Soc., 2016, 138, 10265. 
17 H. Bin, Z. G. Zhang, L. Gao, S. Chen, L. Zhong, L. Xue, C. Yang and Y. Li, J. Am. Chem. Soc., 2016, 138, 4657.

18 R. S. Ashraf, I. Meager, M. Nikolka, M. Kirkus, M. Planells, B. C. Schroeder, S. Holliday, M. Hurhangee, C. B. Nielsen, H. Sirringhaus and I. McCulloch, J. Am. Chem. Soc., 2015, 137, 1314.

19 Y. Deng, J. Liu, J. Wang, L. Liu, W. Li, H. Tian, X. Zhang, Z. Xie, Y. Geng and F. Wang, Adv. Mater., 2014, 26, 471.

20 W. Chen, M. Xiao, L. Han, J. Zhang, H. Jiang, C. Gu, W. Shen and R. Yang, ACS Appl. Mater. Interfaces, 2016, 8, 19665.

21 M. Zhang, Y. Gu, X. Guo, F. Liu, S. Zhang, L. Huo, T. P. Russell and J. Hou, Adv. Mater., 2013, 25, 4944.

22 J. You, L. Dou, K. Yoshimura, T. Kato, K. Ohya, T. Moriarty, K. Emery, C. C. Chen, J. Gao, G. Li and Y. Yang, Nat. Commun., 2013, 4, 1446.

23 Z. He, B. Xiao, F. Liu, H. Wu, Y. Yang, S. Xiao, C. Wang, T. P. Russell and Y. Cao, Nat. Photonics, 2015, 9, 174.

24 M. Zhang, X. Guo, S. Zhang and J. Hou, Adv. Mater., 2014, 26, 1118. 25 Y. Zou, A. Najari, P. Berrouard, S. Beaupré, B. R. Aïch, Y. Tao and M. Leclerc, J. Am. Chem. Soc., 2010, 132, 5330.

26 E. Zhou, J. Cong, K. Tajima, C. Yang and K. Hashimoto, Macromol. Chem. Phys., 2011, 212, 305.
27 E. Zhou, J. Cong, K. Tajima, C. Yang and K. Hashimoto, J. Phys. Chem. C, 2012, 116, 2608.

28 J. W. Jung, J. W. Jo, E. H. Jung and W. H. Jo, Org. Electron., 2016, 31, 149.

29 P. Berrouard, F. Grenier, J. R. Pouliot, E. Gagnon, C. Tessier and M. Leclerc, Org. Lett., 2011, 13, 38.

30 J. E. Donaghey, R. S. Ashraf, Y. Kim, Z. G. Huang, C. B. Nielsen, W. Zhang, B. Schroeder, C. R. G. Grenier, C. T. Brown, P. D'Angelo, J. Smith, S. Watkins, K. Song, T. D. Anthopoulos, J. R. Durrant, C. K. Williamsa and I. McCullocha, J. Mater. Chem., 2011, 21, 18744. 31 X. Qiao, Q. Wu, H. Wu, D. Wang and H. Li, Polym. Chem., 2016, 7, 807.

32 B. Carsten, J. M. Szarko, H. J. Son, W. Wang, L. Lu, F. He, B. S. Rolczynski, S. J. Lou, L. X. Chen and L. Yu, J. Am. Chem. Soc., 2011, 133, 20468.

33 R. S. Bhatta and M. Tsige, ACS Appl. Mater. Interfaces, 2014, 6, 15889. 34 Q. Wu, M. Wang, X. Qiao, Y. Xiong, Y. Huang, X. Gao and H. Li, Macromolecules, 2013, 46, 3887.

35 G. Y. Chen, Y. H. Cheng, Y. J. Chou, M. S. Su, C. M. Chen and K. H. Wei, Chem. Commun., 2011, 47, 5064.

36 G. Li, V. Shrotriya, J. S. Huang, Y. Yao, T. Moriarty, K. Emery and Y. Yang, Nat. Mater., 2005, 4, 864. 